\title{
Prediction of delayed cerebral ischaemia after subarachnoid haemorrhage by computed tomography
}

\author{
F MOHSEN, * S POMONIS, R ILLINGWORTH \\ From the Regional Department of Neurosurgery and Department of Radiology, Central Middlesex Hospital, \\ London, UK
}

SUMMARY Computed tomography was performed in 100 patients within 4 days of aneurysmal subarachnoid haemorrhage. The CT appearances have been divided into five grades by the thickness and extent of the subarachnoid blood. Delayed cerebral ischaemia occurred in $62.5 \%$ of patients with most blood on CT, in $33.3 \%$ of those in the next grade and in none of the other grades with less amounts of blood. The outcome from delayed ischaemia was worse in those with most CT blood.

Delayed cerebral ischaemia causes more deaths and disability than rebleeding in patients admitted to neurosurgical departments after aneurysmal subarachnoid haemorrhage (SAH). ${ }^{2}$ Once ischaemia has developed there is no certainly successful treatment and identification of patients particularly at risk may be of value in allowing early treatment or preventative measures to be undertaken.

Computed tomography (CT) shows the amount and extent of blood in the basal cisterns and other areas of the subarachnoid space, and it has been found that patients with most blood on CT tend to have a worse outcome. ${ }^{3-8}$ This may be related to the severity of the initial haemorrhage, or to an increased incidence of rebleeding or ischaemia, and it might be expected that blood in the subarachnoid space in relation to major cerebral vessels would be a factor in the production of angiographically demonstrated vasospasm and hence ischaemia, rather than rebleeding. However, only two of the previous studies have excluded from analysis patients who rebled ${ }^{4}$ and the other four considered the outcome in all patients, however caused.$^{3-7} \mathrm{We}$ have studied specifically the risk of developing delayed cerebral ischaemia, and also the outcome of

Address for reprint requests: R Illingworth, Regional Department of Neurosurgery, Central Middlesex Hospital, Acton Lane, London, NW10 7NS, UK.

*Present address: Hairmyres Hospital, East Kilbride, Lanarkshire, Scotland.

Received 21 October 1983 and in revised form 13 April 1984. Accepted 18 April 1984 this event, in relation to the thickness and extent of the subarachnoid blood in CT performed soon after SAH.

\section{Material and methods}

One hundred and twenty five patients with proven aneurysmal SAH were scanned within four days of bleeding between July 1977 and December 1982. To study the risk of cerebral ischaemia 25 patients have been excluded; 16 because they rebled after admission, four who died or were disabled by the initial haemorrhage, two because of doubt about the cause of deterioration, one who had an urgent operation for intracerebral haematoma, and two who died from causes other than SAH or cerebral ischaemia. The rebleeds were confirmed by CT in seven, and by lumbar puncture (LP) in two, but not in the remaining seven who died suddenly. The ages, sexes and sites of aneurysms of the remaining 100 patients, who all improved after SAH to at least grade 3, are shown in table 1 .

CT scans were performed with an EMI 1010 scanner with $160 \times 160$ matrix, slice thickness of $10 \mathrm{~mm}$ and scanning time of 80 seconds. The unenhanced scans were reviewed by a neuroradiologist (FM) without access to clinical information and allocated to three grades of Hypodense (fig 1), Isodense (fig 2), and Hyperdense, by the density of the basal cisterns and subarachnoid space in relation to brain density. The Hyperdense scans were further divided into three grades to give an approximate indication of the subarachnoid blood in thickness and extent.

Grade I indicates a localised thin layer of blood ( $<2 \mathrm{~mm}$ ) in the basal cisterns on one side or in one sylvian fissure only, without diffuse deposition of blood in the subarachnoid space (fig 3).

Grade II indicates a localised thick layer of blood $(\geqslant 2$ $\mathrm{mm}$ ) in the basal cisterns, sylvian fissure or interhemispheric fissure without diffuse deposition in the subarach- 
Table 1 Sex and age in years in 100 patients

\begin{tabular}{|c|c|c|c|c|c|c|c|c|c|}
\hline & $11-20$ & $21-30$ & $31-40$ & $41-50$ & $51-60$ & $61-70$ & $71+$ & Total & Mean \\
\hline $\begin{array}{l}\mathrm{M} \\
\mathrm{F}\end{array}$ & $\begin{array}{l}2 \\
1\end{array}$ & $\begin{array}{l}3 \\
6\end{array}$ & $\begin{array}{r}9 \\
16\end{array}$ & $\begin{array}{r}8 \\
16\end{array}$ & $\begin{array}{r}9 \\
14\end{array}$ & $\begin{array}{r}4 \\
11\end{array}$ & $\begin{array}{l}0 \\
1\end{array}$ & $\begin{array}{l}35 \\
65\end{array}$ & $\begin{array}{l}44 \cdot 1 \\
46 \cdot 0\end{array}$ \\
\hline $\begin{array}{l}A C \\
37\end{array}$ & $\begin{array}{l}I C \\
3\end{array}$ & & $\begin{array}{l}M C \\
13\end{array}$ & $\begin{array}{l}\text { Dis } \\
6\end{array}$ & urysms & $\underset{2}{\text { Bas. + PICA }}$ & $\begin{array}{l}\text { Multiple } \\
11\end{array}$ & & $\begin{array}{l}\text { Total } \\
100\end{array}$ \\
\hline
\end{tabular}

noid space (fig 4); or diffuse deposition without a thick layer.

Grade III indicates diffuse deposition of blood in the subarachnoid space and basal cisterns and basal cisterns filled with a thick layer of blood $(\geqslant 2 \mathrm{~mm})$ on at least one side (figs 5 and 6 ).

Exact measurement of the thickness of blood layers was often difficult and this will be considered in the discussion.
Despite this no difficulty was found in allocating the scans to a single category.

The clinical grading on admission was by the method of Nishioka;' 56 patients were admitted in grade 2, 24 in grade 3 and 20 in grade 4.

The outcome in each patient was determined at two months after SAH by review of the case notes and by outpatient attendance in most surviving patients. Five

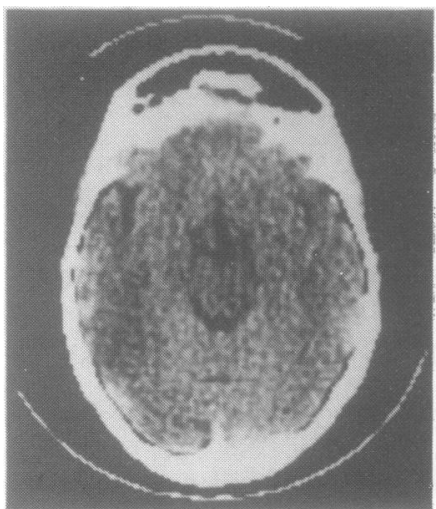

Fig 1

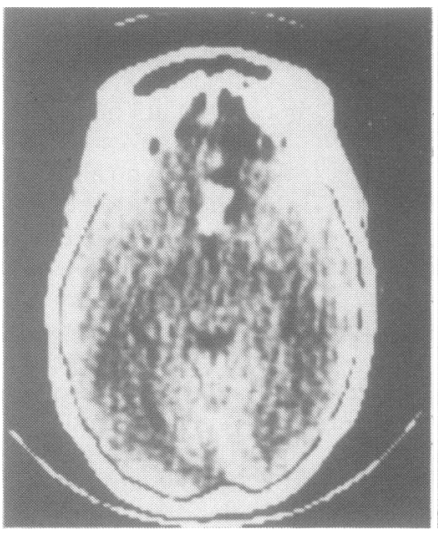

Fig 4

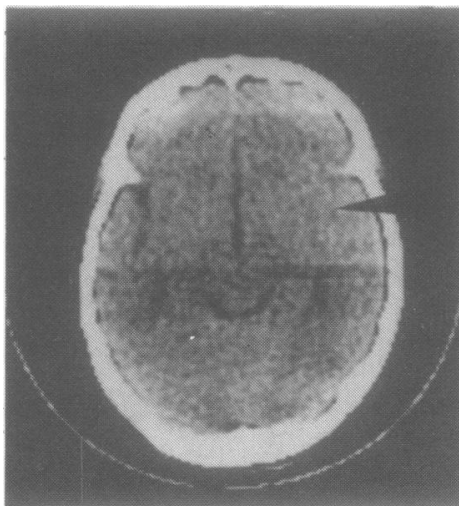

Fig 2

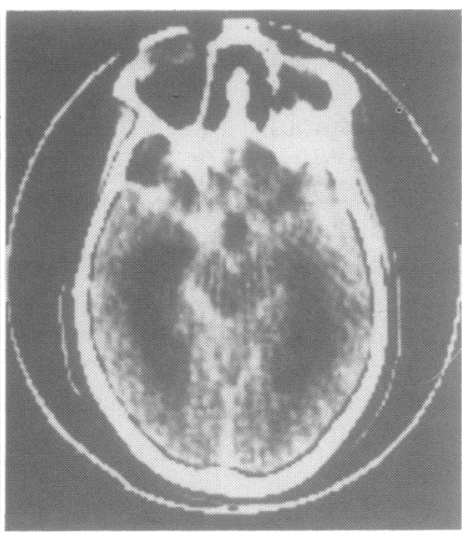

Fig 5

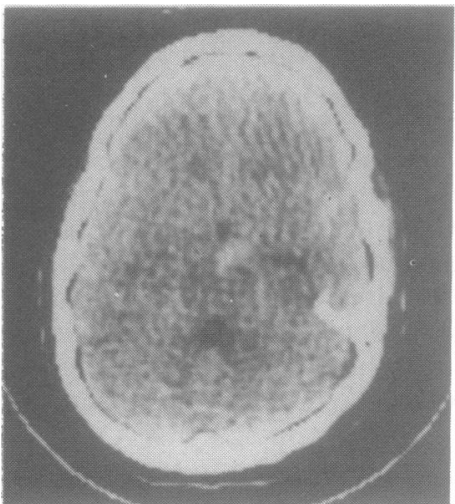

Fig 3

Fig 1 CT Hypodense: hypodense basal cisterns and sylvian fissures.

Fig 2 CT Isodense: isodense right sylvian fissure.

Fig 3 CT Hyperdense I: localised thin layer of blood in interpeduncular cistern and right cisterna ambiens.

Fig 4 CT Hyperdense II: localised thick layer of blood in the inferior part of the interhemispheric fissure.

Fig 5 CT Hyperdense III: diffuse blood in the basal cisterns with localised thick layer on the left side. 

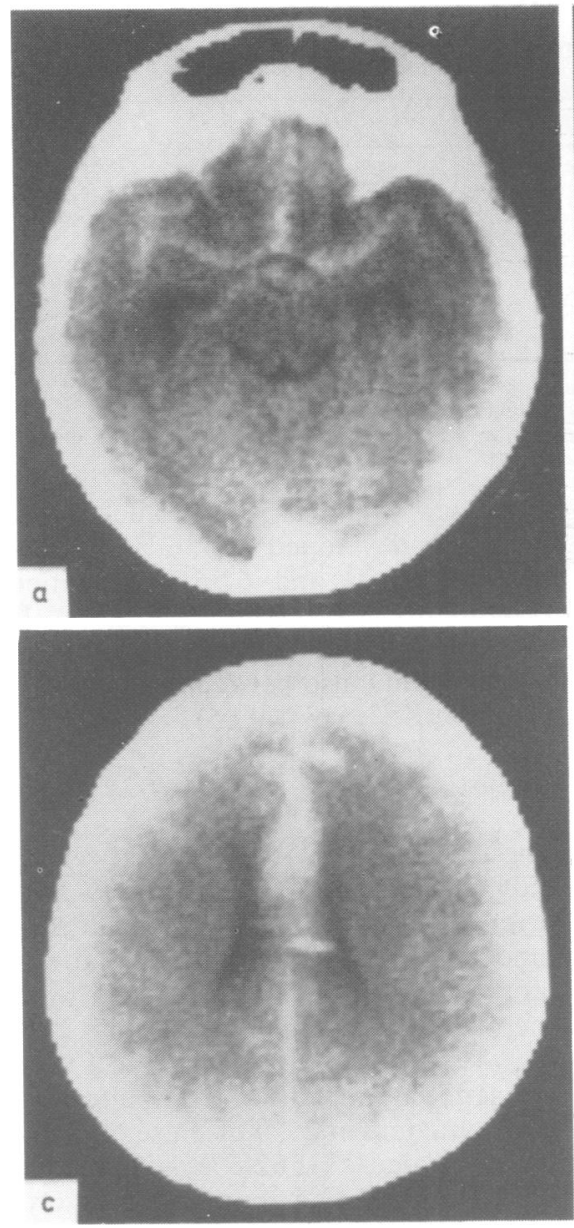

grades of outcome have been used: ${ }^{10}$

Grade I good recovery: full and independent life, with or without minimal neurological deficit; working in previous employment.

Grade 2 moderately disabled: neurological or intellectual impairment but independent; not working or in reduced capacity;

Grade 3 severely disabled: conscious but totally dependent on others.

Grade 4 vegetative survival.

Grade 5 dead.

For evaluation of the results the outcomes of grades 1 and 2 have been considered good, and grades 3, 4 and 5 poor.

Delayed neurological deterioration believed to be due to cerebral ischaemia, occurred in 42 patients, and was recognised by gradual onset of progressive neurological deterioration, with development of hemispheric deficit and usually depression of conscious level. This was confirmed and recurrent bleeding excluded by repeat CT in 27 , by CT

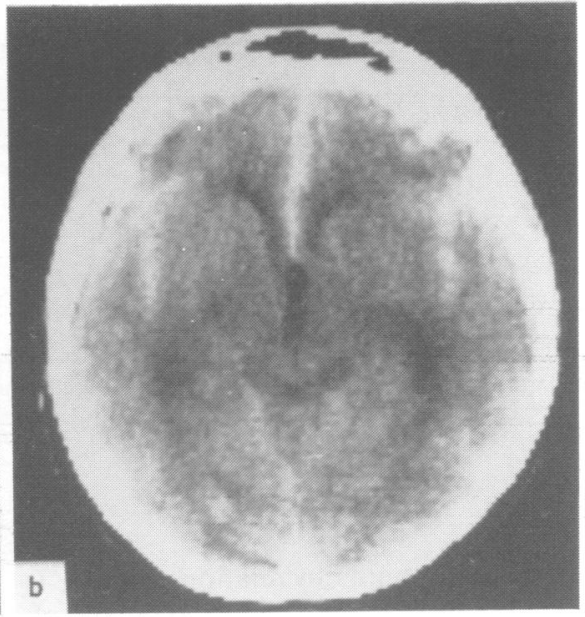

Fig 6 CT Hyperdense III: three slices from one scan. (a) and (b) show diffuse blood in the basal cisterns, interhemispheric fissure and both sylvian fissures. (c) shows a localised thick layer in the interhemispheric fissure.

and lumbar puncture in two, and by lumbar puncture alone in one. Repeat CT showed focal areas of low density in all 29 , with mid-line shift in six. The basal cisterns had become hypodense in 19 , and showed less blood than initially in 10 . Two patients had severe vasospasm shown on repeat angiography. Sixty nine per cent of cases of delayed ischaemia occurred in days 5 to 11 after SAH and when focal neurological signs developed these were always related anatomically to the cerebral artery from which the ruptured aneurysm arose.

Intracranial operation to treat the ruptured aneurysm was performed in 82 patients, $14(17 \cdot 1 \%)$ within the first week after SAH, $39(47.6 \%)$ in the second week and 29 $(35.4 \%)$ later than that.

Arterial hypertension was considered to be present when patients were known treated hypertensives, or when sustained diastolic pressures of more than $90 \mathrm{~mm} \mathrm{Hg}$ were recorded after admission. The study was retrospective, the clinical management not being modified by any expectation of development of cerebral ischaemia. 
Table 2 Outcome at 2 months in relation to CT appearance in 100 patients (\%)

\begin{tabular}{|c|c|c|c|c|c|}
\hline \multirow[t]{2}{*}{ Outcome grades } & \multicolumn{5}{|l|}{$C T$ grades } \\
\hline & Hypodense & Isodense & Hyperdense I & Hyperdense II & Hyperdense III \\
\hline 1 & 3 & 5 & $\left.{ }^{8}\right\}(100 \cdot 0)$ & $\left.{ }^{28}\right\}(91 \cdot 7)$ & $\left.{ }^{26}\right\}(60 \cdot 4)$ \\
\hline 2 & - & - & -120 & $5 J$ & $3 J$ \\
\hline $\begin{array}{l}3 \\
4\end{array}$ & - & - & - & $\left.\begin{array}{l}1 \\
1\end{array}\right\}(8 \cdot 3)$ & $\left.\begin{array}{l}4 \\
2\end{array}\right\}(39 \cdot 6)$ \\
\hline 5 & - & - & - & ${ }_{1}$ & ${ }_{13} J$ \\
\hline
\end{tabular}

Notes: Outcome grade 3,4 and 5 due to delayed cerebral ischaemia.

Hyperdense III $v$ all other grades: $p<0.001\left(x^{2}\right.$ with Yates correction $\left.=14.7\right)$

Hyperdense III v Hyperdense II: $\mathrm{p}<0.01\left(\chi^{2}\right.$ with Yates correction $\left.=8.8\right)$

\section{Results}

The outcomes at two months in relation to the CT grading are given in table 2 . The clinical outcome of grades 3, 4 and 5 was due in all instances to delayed cerebral ischaemia and most cases occurred in patients with CT Hyperdense III in which group $39.6 \%$ had poor outcome. In patients with CT Hyperdense II there were $8.3 \%$ with poor outcome, and all 16 patients with Hypodense, Isodense and Hyperdense I CT had good outcome. The difference in outcome between those with CT Hyperdense III and all other CT grades is significant $(p<0.001)$ and also between CT Hyperdense III and Hyperdense II $(p<0.01)$.

Poor outcome due to delayed cerebral ischaemia occurred in 22 patients and 20 others showed temporary deterioration and then recovered. Table 3 shows that in these 42 patients, who all had CT Hyperdense II or III, the outcome was worse in those with most subarachnoid blood. $75 \%$ of 12 patients with CT Hyperdense II who became ischaemic made good recoveries, compared to only $36.7 \%$ of 30 with CT Hyperdense III. $(p=0.03)$.

From these results it is possible to determine the risk of the development of delayed cerebral

Table 3 Outcome at 2 months in relation to $C T$ appearance in 42 patients developing delayed cerebral ischaemia (\%)

\begin{tabular}{|c|c|c|}
\hline \multirow[t]{2}{*}{ Outcome grades } & \multicolumn{2}{|l|}{$C T$ grades } \\
\hline & Hyperdense II & Hyperdense III \\
\hline 1 & $\left.{ }^{5}\right\}(75 \cdot 0)$ & $\left.{ }^{9}\right\}(36 \cdot 7)$ \\
\hline 2 & ${ }_{4} \int(100)$ & $2 \int(00)$ \\
\hline 3 & $1)$ & $4)$ \\
\hline 4 & $1\}(25 \cdot 0)$ & $2\}(63 \cdot 3)$ \\
\hline 5 & 1) & 13J \\
\hline
\end{tabular}

ischaemia, whatever its outcome. Table 4 shows that ischaemia developed in $33.3 \%$ of patients with CT Hyperdense II and $62.5 \%$ of patients with CT Hyperdense III. The difference between CT Hyperdense III and all other grades is significant ( $p$ $<0.001$ ) and also between CT Hyperdense III and Hyperdense II $(\mathrm{p}<0.05)$.

\section{Discussion}

These results show that delayed cerebral ischaemia only occurred in patients who had a localised thick layer of subarachnoid blood or diffuse deposition of blood or both. The more blood that was present, the more likely it was that ischaemia would occur and the more severe the effects of that ischaemia would be. Thus, in patients with CT Hyperdense II ischaemia occurred in $33.3 \%$ and was followed by poor outcome in $25 \%$ of these, and in patients with CT Hyperdense III $62.5 \%$ developed ischaemia and $63.3 \%$ of these had poor outcomes. Over $70 \%$ of all cases of cerebral ischaemia occurred in patients with most blood on CT (Hyperdense III) and no cases occurred in those with Hypodense, Isodense or Hyperdense I CT.

Previous publications on CT in SAH have assessed the subarachnoid blood in extent, ${ }^{46}$ in thickness, ${ }^{7}$ or just by density. ${ }^{3}$ We have followed Fisher $e t$ $a l^{5}$ in attempting to assess both the thickness and extent of blood in the basal cisterns, sylvian fissures

Table 4 Risk of developing delayed cerebral ischaemia in relation to $C T$ appearances (\%)

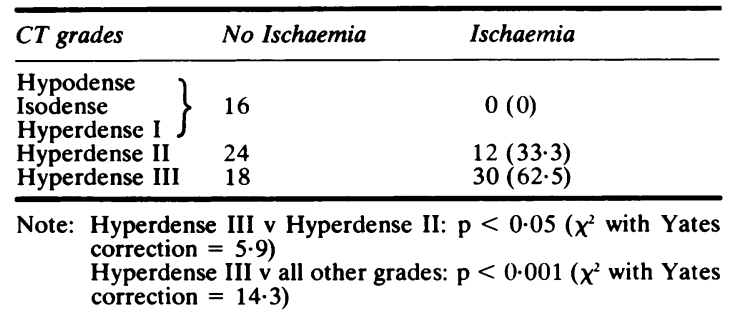


and other areas of the subarachnoid space. As Fisher $e t a l^{5}$ have described, there are difficulties in measuring thickness due to the irregular dimensions and variable planes of the cisterns and fissures, the different local concentrations of blood, and problems of measurement due to partial volume effect, especially with a thick CT slice. The method of assessing the thickness of blood layers is therefore to some extent subjective. It should also be noted that the CT Hyperdense II group is not homogeneous. However, this grouping appears to be valid since six of the 26 patients with diffuse deposition alone developed ischaemia, as did four of 10 patients with localised thick layer alone.

Despite differences of method in earlier studies it is possible to make some comparisons of results. In the study of Bell et al, ${ }^{3}$ which did not exclude rebleeds, $28 \%$ of 43 patients with Hyperdense CT had poor outcome which is similar to our own figure of $24 \%$ ( 22 of 92 with all Hyperdense CT grades). Davis et $\mathrm{al}^{4}$ found deterioration in $50 \%$ of 22 patients in their two CT grades with most blood, roughly equivalent to our CT Hyperdense II and III in which ischaemia affected 42 out of 84 . The equivalent figures in the paper of Richardson and Gurusinghe $^{7}$ was $65 \%$ for patients with blood in layers of 2 to $5 \mathrm{~mm}$, and more than $5 \mathrm{~mm}$ thick. Higher figures of deterioration have been described by Fisher $e t a^{5}$ in whose group of 24 with a thick layer of subarachnoid blood, 23 (96\%) developed cerebral ischaemia. However, only eight $(35 \%)$ of those deteriorated patients appear to have died or been left with significant disability, half the figure for poor outcome in our equivalent patients. Kinugawa et $a l^{6}$ reported $80 \%$ of deaths in patients with most CT subarachnoid blood.

We have considered the possibility that our findings may be related to factors other than the CT appearances. Table 5 shows the incidence of hypertension, the ages, and the percentage of patients admitted in clinical grade 2 with different CT grades. It can be seen that although there was no difference in the incidence of hypertension, there was an excess of older patients with CT Hyperdense III. However, these factors were not related to the development of ischaemia since in the group with CT Hyperdense III the mean age of patients with ischaemia was 47.9 years, and of those without was 51.3 years. Furthermore in this group, although there were fewer patients admitted in clinical grade 2 than in the other CT grades, the incidence of ischaemia in this clinical grade $(13 / 20=65 \%)$ did not differ from those admitted in clinical grade 3 $(9 / 15=60 \%)$, and in clinical grade $4(8 / 13=$ $61.5 \%$ ). However, patients admitted in clinical grade 2 and who became ischaemic fared rather better than those ischaemic patients admitted in worse clinical grades. Six of $13(46 \cdot 2 \%)$ had poor outcome compared to $8 / 9(88.9 \%)$ of those admitted in grade 3 , and $5 / 8(62.5 \%)$ of those admitted in grade 4 . These differences are not significant but clinical grade on admission is likely to remain a factor in outcome.

The timing and results of operations could also have been factors in outcome. Table 6 shows that less patients in the group with most blood on CT were operated on, $70.8 \%$ compared to $88.9 \%$ of those with CT Hyperdense II and $100 \%$ in all other CT grades, and also that these patients were operated on later. Both these differences were due to the development of cerebral ischaemia, and were not a result of interpretation of the CT findings, the significance of which was not known at that time. There were seven poor results in the 34 operated patients with CT Hyperdense III, but three of these results were due to pre-operative ischaemia and the other four are insufficient to influence the results.

There is one other factor which is not mentioned in any other study. This is the use of antifibrinolytic drugs, the policy on which changed in this department during the years covered by the study. In 1981, as a result of our finding that antifibrinolytic drugs conferred no overall benefit in terms of reduction of mortality 11 their use was discontinued. This meant that 67 patients in the earlier part of the study were given antifibrinolytic drugs and 33 later were not.

Table 5 Age, hypertension and clinical grade on admission in relation to CT appearance

\begin{tabular}{|c|c|c|c|}
\hline & \multicolumn{3}{|l|}{$C T$ grades } \\
\hline & $\begin{array}{l}\text { Hypodense } \\
\text { Isodense } \\
\text { Hyperdense I }\end{array}$ & Hyperdense II & Hyperdense III \\
\hline $\begin{array}{l}\text { Mean age (years) } \\
\text { Age over } 60 \\
\text { Hypertension } \\
\text { Grade } 2 \text { on admission }\end{array}$ & $\begin{array}{l}42.6 \\
12.5 \% \\
25 \cdot 0 \% \\
87.5 \%\end{array}$ & $\begin{array}{l}42 \cdot 0 \\
8 \cdot 3 \% \\
27 \cdot 8 \% \\
61 \cdot 1 \%\end{array}$ & $\begin{array}{l}49 \cdot 0^{*} \\
22 \cdot 9 \% \\
33 \cdot 3 \% \\
41 \cdot 7 \% \dagger\end{array}$ \\
\hline
\end{tabular}

*Mean age in Hyperdense III patients with ischaemia 47.9 years.

Mean age in Hyperdense III patients without ischaemia 51.3 years.

†Ischaemia developed in $65.0 \%$ of hyperdense III patients admitted in grade $2,60 \%$ in grade $3,61.5 \%$ in grade 4 . 
Table 6 Timing of operation and outcome in relation to CT appearance

\begin{tabular}{|c|c|c|c|}
\hline & \multicolumn{3}{|l|}{$C T$ grades } \\
\hline & $\begin{array}{l}\text { Hypodense } \\
\text { Isodense } \\
\text { Hyperdense I }\end{array}$ & Hyperdense II & Hyperdense III \\
\hline $\begin{array}{l}\text { Number operated (poor } \\
\text { outcome) } \\
\text { Number non-operated }\end{array}$ & $16(0)$ & $32(1)$ & $34(7)^{*}$ \\
\hline $\begin{array}{l}\text { (poor outcome) } \\
\text { Operated days } 0-7 \\
\text { Operated days 8-14 } \\
\text { Operated days } 14+\end{array}$ & $\begin{array}{l}0 \\
31 \cdot 3 \% \\
42 \cdot 7 \% \\
25 \cdot 0 \%\end{array}$ & $\begin{array}{c}4(2) \\
12 \cdot 5 \% \\
62 \cdot 5 \% \\
25 \cdot 0 \%\end{array}$ & $\begin{array}{l}14(12) \\
14 \cdot 7 \% \\
35 \cdot 3 \% \\
50 \cdot 0 \%\end{array}$ \\
\hline
\end{tabular}

${ }^{*}$ Pre-operative neurological deficit due to ischaemia in three.

Among the earlier 67 there were 33 with CT Hyperdense III and of these $20(60.6 \%)$ developed cerebral ischaemia with poor outcome in $16(80 \%)$. The equivalent figures for 15 patients with CT Hyperdense III and no antifibrinolytic drugs are ischaemia in $10(66.7 \%)$ and poor outcome in 3 $(30.0 \%)$. The difference in outcome from ischaemia is significant; $p=0.011$ (Fisher's Exact Test). This suggests that the use of antifibrinolytic drugs did not cause the delayed cerebral ischaemia but may have been a factor in the poor recovery from this event. Since the action of antifibrinolytic drugs is to delay the absorption of the subarachnoid blood, this finding may give some support to the practice of early operative removal of blood from around the aneurysm to reduce the risk of delayed ischaemia.

The application of our findings in clinical management does not appear clear since there are two distinct policies on timing of aneurysm surgery. Those who operate early believe that ischaemia may thereby be prevented, and if not it can be more effectively treated once the patient is no longer at risk of rebleeding. On the other hand the late operators believe that effective measures to prevent ischaemia can be used and that the best operative results can be achieved once the period of risk of ischaemia has passed. At least the identification of patients with little or no risk of ischaemia may allow early operation to be performed with confidence that delayed deterioration is unlikely, and the identification of patients with high risk of ischaemia may allow better evaluation of methods to prevent or treat this potentially disastrous event. Early CT appearances should be considered in addition to clinical grade on admission as a major factor in predicting the outcome after aneurysmal SAH.

We are grateful to Mr JM Rice Edwards, for permission to use patients admitted under his care, to $\mathrm{Mr} \mathrm{S}$ Edmeads, Department of Community Medicine, Middlesex Hospital Medical School for the statistical analyses and to Miss A Mahony for much secretarial assistance.

\section{References}

' Illingworth RD. Surgical management of subarachnoid haemorrhage due to ruptured intracranial aneurysm. In: Greenhalgh RM, Rose FC, eds. Progress in Stroke Research 1. London: Pitman Medical 1979;377-86.

${ }^{2}$ Maurice-Williams RS. Ruptured intracranial aneurysms: has the incidence of early rebleeding been overestimated? J Neurol Neurosurg Psychiatry 1982;45:774-9.

${ }^{3}$ Bell BA, Kendall BE, Symon L. Computed Tomography in aneurysmal subarachnoid haemorrhage. $J$ Neurol Neurosurg Psychiatry 1980;43:522-4.

${ }^{4}$ Davis JM, Davis KR, Crowell RM. Subarachnoid hemorrhage secondary to ruptured intracranial aneurysm: Prognostic significance of cranial CT. AJNR 1980;1:17-21.

${ }^{5}$ Fisher CM, Kistler JP, Davis JM. Relation of cerebral vasospasm to subarachnoid hemorrhage visualised by Computerized Tomographic Scanning. Neurosurgery 1980;6:1-8.

${ }^{6}$ Kinugawa K, Horiike N, Nobuoka J. Clinical prognosis estimated by $\mathrm{CT}$ scan findings on patients in the acute stage after rupture of a cerebral aneurysm. Neurological Surgery. Abstracts of the 7th International Congress of Neurological Surgery. München 1981;307.

${ }^{7}$ Richardson AE, Gurusinghe NT. Use of Computerized Tomography in predicting cerebral vasospasm in Subarachnoid Haemorrhage. Neurological Surgery. Abstracts of the 7th International Congress of Neurological Surgery. München 1981;114.

${ }^{8}$ Illingworth R, Mohsen F, Pomonis S. The value of CT in subarachnoid haemorrhage as a guide to clinical outcome. In: Greenhalgh RM, Rose FC, eds. Progress in Stroke Research 2. London: Pitman Medical 1983:254-66.

${ }^{9}$ Nishioka U. Report on the co-operative study of intracranial aneurysm and subarachnoid haemorrhage. Section VII, Part 1. Evaluation of the conservative management of ruptured intracranial aneurysm. $J$ Neurosurg 1966;25:574-92.

${ }^{10}$ Jennett B, Bond MR. Assessment of outcome after severe brain damage. Lancet 1975; 1:480-4.

"Ameen AA, Illingworth R. Antifibrinolytic treatment in the pre-operative management of subarachnoid haemorrhage caused by ruptured intracranial aneurysm. J Neurol Neurosurg Psychiatry 1981;44:220-6. 